\title{
The economics of tobacco control (Part 2): evidence from the ITC Project
}

\author{
Corné van Walbeek
}

\section{INTRODUCTION}

The empirical evidence for the effectiveness of excise tax increases as a tool for tobacco control and for generating government revenue is overwhelming. Although initially this evidence was generated primarily in high-income countries, the past two decades has seen much evidence originating in low-income and middle-income countries. The findings are broadly similar. The answer to the question, "Are excise taxes effective as a tobacco control instrument?" is an unambiguous "Yes."

This supplement considers secondary questions. For example, how do tax and/ or price increases affect different demographic groups' smoking behaviour? How does the tax structure influence the effectiveness of excise tax increases? Do certain individual or community characteristics impact the effectiveness of excise tax increases? Are minimum price laws (MPLs) equally/more/less effective than tobacco excise tax increases to reduce smoking? How do smokers avoid tax or price increases?

These topics do not question the effectiveness of excise tax increases as a tobacco control instrument, but they allow researchers and policymakers to gain a deeper understanding of the complexities associated with tax and price increases. While time series data and cross-sectional data were sufficient to establish the effectiveness of excise tax increases as a tobacco control tool, many of the secondary questions require more sophisticated data. Longitudinal data allow researchers to do exactly that.

\section{THE INTERNATIONAL TOBACCO CONTROL PROJECT}

The International Tobacco Control Policy Evaluation Project (ITC Project), founded in 2002, systematically evaluates key policies of the WHO Framework Convention on Tobacco Control (FCTC). Starting with four countries (Canada, the USA, the UK and Australia), it has expanded rapidly and is currently in 22 countries,

Correspondence to Professor Corné van Walbeek, Room 5.05, School of Economics, Middle Campus, University of Cape Town, Rondebosch, Cape Town 7700, South Africa; cwalbeek@gmail.com containing more than $50 \%$ of the world's population, $60 \%$ of the world's smokers and $70 \%$ of the world's tobacco users.

This supplement consists of 13 papers. Of these, 10 consider individual countries (China (2), Malaysia, Mauritius, Mexico (2), South Korea, Uruguay, the USA and Zambia), while the other 3 studies consider groups of countries.

Although each paper is a stand-alone study, there are some common themes across these papers: (1) the impact of tax and price measures on individual behaviour, (2) the impact of the neighbourhood environment on smoking behaviour and (3) an analysis of policy on the effectiveness of excise tax changes.

\section{The impact of tax and price measures} on individual behaviour

Four papers explicitly consider smokers' tax avoidance strategies. Cornelius et $a l^{1}$ consider US smokers' cigarette purchasing patterns by different types of packaging over a 9 -year period. Despite the fact that cigarettes purchased in cartons are substantially cheaper than those purchased in single packs, there has been a decrease in the proportion of cigarettes bought in cartons. There has been a substantial increase in the proportion of cigarettes sold in multipacks, which are cheaper per pack than single packs, but more expensive per pack than cigarettes sold in cartons. Cornelius et al ${ }^{1}$ also find that there has been an increase in the number of people who report buying their cigarettes from locations commonly associated with tax avoidance, such as dutyfree shops and Indian reservations.

Brown $e t a l^{2}$ find a substantial increase in roll-your-own cigarette use in the UK, France, Germany and the Netherlands between 2006 and 2012. Roll-your-own tobacco is substantially cheaper than manufactured cigarettes and more than threequarters of roll-your-own users indicate that the lower price drove their decision to buy roll-your-own cigarettes. The authors find that roll-your-own users were more likely to have lower incomes and lower education than smokers of manufactured cigarettes.

Curti et $a l^{3}$ analyse how price differences in legal manufactured, illegal manufactured and roll-your-own cigarettes in Uruguay have changed smokers' purchasing behaviour. They find that an increase in the price of legal cigarettes, relative to the price of roll-your-own cigarettes, has encouraged smokers to switch to roll-your-own cigarettes. However, they do not find statistically significant evidence that an increase in the price of legal cigarettes, relative to the price of illegal cigarettes, encourages smokers to purchase more illegal cigarettes, although there is a suggestion that this might be the case.

Li et al investigate how changes in cigarette prices affect smokers' brand choice in China. Cigarettes are taxed in different price tiers, resulting in a wide dispersion of prices. The study aims to address the Chinese government's concern that an excise tax increase would encourage smokers to switch to cheaper brands. The authors find that an increase in the price of cigarettes would increase the likelihood of tier-switching, but that the magnitude of the switch is not very large. The authors also find that low-income and less-educated groups are more likely to switch tiers than higher socioeconomic groups. The authors argue that the Chinese officials' concern is largely misplaced.

The overarching conclusion of these four studies is that people respond to incentives. When cigarette prices increase, smokers reduce their consumption and some may even quit completely, but for many smokers this is not an option (yet), and they employ a variety of means to minimise the impact of the price increase. The challenge for policymakers is to design the tax system such that it meets public health objectives. Furthermore, even though cross-country studies have shown that the link between increases in the excise tax and an increase in illicit trade is tenuous, ${ }^{5}$ the threat of illicit trade is real in many countries. For excise tax increases to be effective as a tobacco control tool, it is incumbent on the government to minimise the illicit trade in cigarettes.

Salloum et $a l^{6}$ consider cigarette brand loyalty in Zambia and find that there is a high degree of brand loyalty, especially among older and poorer smokers, despite the fact that the variation in prices across brands is small. Within this context, price has a limited influence on brand choice. Brand choice is predicted mostly by friends, taste and brand popularity.

Many people, especially females, hold the belief that smoking controls weight. This belief could be a reason to start smoking and to prevent quitting. Using data from the four original ITC countries, Shang et $\mathrm{al}^{7}$ investigate whether the 
weight control belief impacts the effectiveness of a variety of tobacco control interventions. The results are mixed. Female (and to a lesser extent, male) smokers in the UK and the USA, who hold the weight control belief, are less responsive to some tobacco control interventions than smokers who do not hold this belief. No systematic pattern was found among smokers in Canada and Australia.

Park et $a l^{8}$ address the question: to what level must the price rise in order for Korean smokers to attempt quitting? They find that, for most smokers, the price has to be substantially higher than its current level. Younger, more educated and heavier (ie, more cigarettes per day) smokers, and those less concerned about the health effects of smoking require a higher price to persuade them to attempt quitting. The authors conclude that tax increases should be supplemented by other interventions to reduce smoking in Korea.

\section{The impact of the neighbourhood environment on smoking behaviour}

Two studies from Mexico consider the impact of the neighbourhood environment on smoking and quitting behaviour. Linking the ITC data to census data on neighbourhood socioeconomic deprivation, Fleischer et $a l^{9}$ find that smoking intensity is lower in relatively deprived neighbourhoods and higher in less deprived neighbourhoods. Within the context of a middle-income country with large income inequalities, this is to be expected. Of greater interest would be neighbourhood differences in smoking prevalence, but the ITC Project does not allow one to answer this question, since it is focused only on the behaviour of smokers.

The second study, by Hall et al, ${ }^{10}$ considers access to single cigarettes in the neighbourhood. Between 2010 and 2012, there was a sharp rise in the accessibility of single cigarettes in Mexico and substantially more people bought single cigarettes. Although the results were not significant, they suggest that smokers who live in a neighbourhood where there is greater access to single cigarettes are less likely to make a quit attempt and are more likely to relapse if they quit.

\section{An analysis of policy on the effectiveness of excise tax changes}

Four papers consider the impact of specific policies on tobacco control outcomes. The first paper, by Azagba et al, ${ }^{11}$ considers the combined impact of an antitobacco mass media campaign and a substantial increase in the excise tax on smoking behaviour in Mauritius. The authors find that the two interventions were associated with a decrease in smoking prevalence and smoking intensity among the remaining smokers.

The second paper, by Huang et al, ${ }^{12}$ estimates by what percentage Chinese smokers decrease their consumption in response to a given percentage change in the price of cigarettes (the conditional price elasticity of demand). In line with previous studies on China, the price elasticity is low compared to most other countries, with the conditional price elasticity estimated to be between -0.12 and -0.14 . The authors find that there are no differential responses to cigarette price increases across education levels. In contrast to most other studies, the number of cigarettes smoked by low-income smokers is not sensitive to changes in the price of cigarettes. This counter-intuitive result can probably be attributed to the very large range of cigarette prices in China. Even among the very poor, the cheapest cigarettes are still relatively affordable.

The third paper, by Liber et al, ${ }^{13}$ considers the impact of the 2011 MPL in Malaysia on the prices of legal and illicit cigarettes. Before the MPL was implemented, $96 \%$ of legal cigarettes were above the MPL and it rose to $98 \%$, subsequently. However, about $90 \%$ of illicit cigarettes were sold below the minimum price before the MPL was implemented and this did not change significantly after the MPL was implemented. Furthermore, there was a slight increase in the proportion of illicit purchases after the imposition of the MPL.

While Article 6 of the WHO FCTC ${ }^{14}$ explicitly refers to the use of price policies as a tool for tobacco control, the experience of Malaysia indicates that minimum price policies (as opposed to excise tax policies) might be misdirected. If the aim of the MPL was to reduce the illicit trade in cigarettes, the evidence shows that the policy was unsuccessful. If the aim was to raise the price of legal cigarettes, it was also largely unsuccessful as the vast majority of legal cigarettes were priced above the minimum at the outset. A better strategy would be to fight the illicit market head-on and increase excise taxes, which in turn will increase the retail price of cigarettes. Whereas the MPL would increase the tobacco industry's profits, an increase in the excise tax would increase government revenue.

The fourth paper, by Shang et al, ${ }^{15}$ considers the association between the tax structure and cigarette price variability, using data from 17 countries. The authors find that mixed (ie, combinations of specific and ad valorem) and tiered tax structures are associated with greater price gaps in the retail price of cigarettes. In countries which have a mixed tax structure, a larger specific component is associated with lower price gaps. The results of this paper strongly support the view that tobacco excise tax structures should be as simple as possible, with a large (or even exclusive) specific component. This view is strongly borne out in the WHO Technical Manual on Tobacco Tax Administration $^{16}$ and the Article 6 Guidelines. $^{17}$

\section{CONCLUSION}

Research on the economics of tobacco control-especially those focusing on the tax-price-consumption relationship-has come a long way in the past 30 years. The ITC Project generates data that allow researchers to investigate tobacco taxrelated issues in much greater detail and at deeper levels of sophistication than ever before. The research made possible with these data enables policymakers to better understand the implications of their policies. It is hoped that the results presented in this supplement will have a positive policy impact not only in the countries in which the studies were performed, but also in countries which may not have such advanced data.

\section{Competing interests None declared.}

Provenance and peer review Not commissioned; internally peer reviewed.

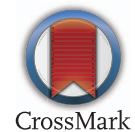

To cite van Walbeek C. Tob Control 2015;24:iii1-iii3.

Tob Control 2015;24:iii1-iii3.

doi:10.1136/tobaccocontrol-2015-052425

\section{REFERENCES}

1 Cornelius ME, Driezen P, Hyland A, et al. Trends in cigarette pricing and purchasing patterns in a sample of US smokers: findings from the ITC US surveys (2002-2011). Tob Control 2015;24:iii4-10.

2 Brown A, Nagelhout G, van den Putte B, et al. Trends and socioeconomic differences in roll-your-own tobacco use: findings from the ITC Europe surveys. Tob Control 2015;24:iii11-16.

3 Curti D, Shang C, Ridgeway W, et al. The use of legal, illegal, and roll-you-own cigarettes to increasing tobacco excise taxes and comprehensive tobacco control policies-findings from the ITC Uruguay survey. Tob Control 2015;24:iii17-24.

4 Li J, White JS, Hu TW, et al. The heterogenous effects of cigarette prices on brand choice in China: implications for tobacco control policy. Tob Control 2015;24:iii25-32.

5 Joossens L, Merriman D, Ross H, et al. How eliminating the global illicit cigarette trade would increase tax revenue and save lives. Paris: International Union Against Tuberculosis and Lung Disease, 2009. 
6 Salloum RG, Goma F, Chelwa G, et al. Cigarette price and other factors associated with brand choice and brand loyalty in Zambia: findings from the ITC Zambia survey. Tob Control 2015;24:iii33-40.

7 Shang C, Chaloupka FJ, Fong GT, et al. Weight control belief and its impact on the effectiveness of tobacco control policies on quit attempts: findings from the ITC 4 Country project. Tob Control 2015;24: iii41-7.

8 Park E, Park S, Cho S, et al. What cigarette price is required for smokers to attempt to quit smoking? Tob Control 2015;24:iii48-55.

9 Fleischer NL, Thrasher JF, Sáenz de Miera Juárez B, et al. Neighborhood deprivation and smoking and quit behavior among smokers in Mexico: findings from the ITC Mexico survey. Tob Control 2015;24: iii56-63.
10 Hall MG, Fleischer NL, Reynales-Shigematsu LM, et al. Increasing availability and consumption of single cigarettes: trends and implications for smoking cessation from the ITC Mexico survey. Tob Control 2015;24:iii64-70.

11 Azagba S, Burhoo P, Chaloupka FJ, et al. Effect of cigarette tax increase in combination with mass media campaign on smoking behavior in Mauritius: findings from the ITC survey. Tob Control 2015;24:iii71-5.

12 Huang J, Zheng R, Chaloupka FJ, et al. Differential responsiveness to cigarette price by education and income among adult urban Chinese smokers. Tob Control 2015;24:iii76-82.

13 Liber AC, Ross H, Omar M, et al. The impact of the Malaysian minimum cigarette price law: findings from the ITC Malaysia survey. Tob Control 2015;iii83-7.
14 World Health Organization. Framework Convention on Tobacco Control. 2003. http://whqlibdoc.who.int/ publications/2003/9241591013.pdf (accessed $2 \mathrm{Apr}$ 2015).

15 Shang C, Chaloupka FJ, Fong GT, et al. The association between tax structure and cigarette price variability: findings from the International Tobacco Control Policy Evaluation (ITC) Project. Tob Control 2015;24:iii88-93.

16 World Health Organization. Technical Manual on Tobacco Tax Administration. 2010. http://whqlibdoc. who.int/publications/2010/9789241563994_eng.pdf (accessed 2 Apr 2015).

17 World Health Organisation. Guidelines for implementation of article 6 of the WHO FCTC. http:// www.who.int/fctc/guidelines/adopted/Guidelines_ article_6.pdf?ua=1 (accessed 2 Apr 2015). 